
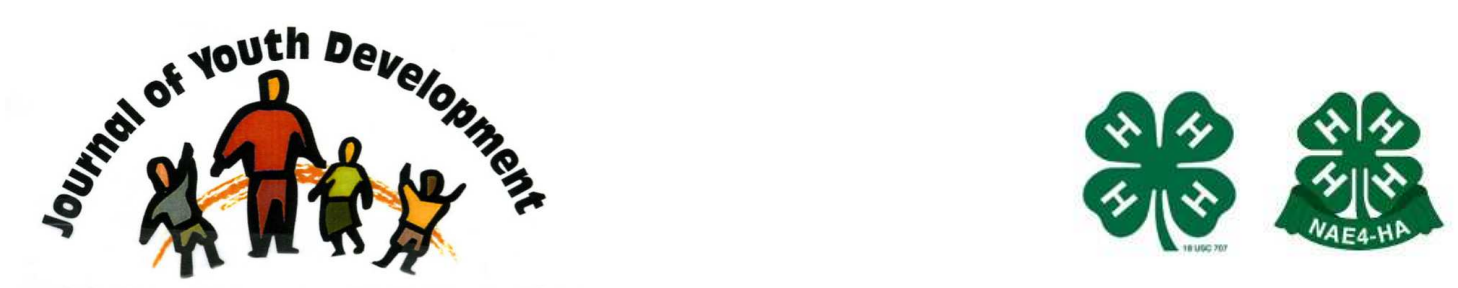

Bridging Research \& Practice

\title{
Opportunities to Develop Programs and Engage Amish Youth in Safety Education
}

\author{
S. Dee Jepsen \\ Department of Food, Ag, \& Bio Engineering \\ The Ohio State University \\ Columbus, $\mathrm{OH}$ \\ jepsen.4@osu.edu \\ Joseph Donnermeyer \\ School of Environment \& Natural Resources \\ The Ohio State University \\ Columbus, $\mathrm{OH}$ \\ donnermeyer.1@osu.edu
}




\title{
JOURNAL OF YOUTH DEVELOPMENT \\ bridging research and practice

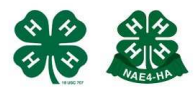

Volume 7, Number 2, Summer 2012

Article 120702FA003

\section{Opportunities to Develop Programs and Engage Amish Youth in Safety Education}

\author{
S. Dee Jepsen and Joseph Donnermeyer \\ The Ohio State University
}

\begin{abstract}
Understanding and designing appropriate educational youth safety programs for the Amish requires an appreciation of their history, their distinctiveness in an American society built on economic, social and cultural change, and how the Amish themselves have changed over the years. The qualitative research study highlighted in this paper sought to determine culturally and age-appropriate curricula useful to community educators interested in youth safety programs for Amish and other conservative Anabaptist groups. Researchers identified rural safety topics of interest to Amish families to include lawn mowers, string trimmers, chemicals, water, livestock, confined spaces, tractors and skid loaders. Parents regularly involved children in daily farm chores, where they made assignments based on the child's physical development, maturity, interest in the task, and birth-order. Findings suggest opportunities for cooperative extension professionals to develop and engage Amish children in safety education programs.
\end{abstract}

\section{Introduction}

Understanding and designing appropriate educational youth safety programs for the Amish requires an appreciation of their history, their distinctiveness in an American society built on economic, social and cultural change, and how the Amish themselves have changed over the years. This qualitative research study sought to determine culturally and age-appropriate curricula useful to community educators interested in youth safety programs for Amish and other conservative Anabaptist groups.

Background on the Evolution of Amish Culture in the U.S.

Amish beginnings date back to the earliest years of the Protestant reformation when a group of reformers in the Swiss city of Zurich expressed concern about the link between government and religion, focused specifically on the use of infant baptism as a way to maintain an accounting of the population for military duty among males, and for taxes (Beachy, 2011). Although they approved of the Protestant Reformation, they did not believe it had gone far enough. Known at 
the time as the Anabaptist movement, it spread north along the Rhine River through various provinces of France, Germany, and the Netherlands, developing into groups that are today known as the Mennonites and Brethren, plus the Amish themselves. The Hutterite colonies found throughout the Upper Plains states and the western provinces of Canada can be traced back to Anabaptist groups from Russia, but who originally came there from areas along the Danube River in eastern Europe.

The Amish are named after one of their early leaders, Jacob Amman, who spearheaded a dialogue in 1693 between the Anabaptists from the Alsace region in France with several of the remaining Anabaptist groups on the Swiss side of the Rhine River. Differences could not be resolved, and 1693 is generally accepted as the date for the beginning of the group which we now know as the Amish (Hostetler, 1993; Beachy, 2011).

The lure of religious freedom and an opportunity to own their own land brought the Amish and many other persecuted religious minorities to America's shores (Nolt, 2003). Through the port of Philadelphia in the 1700s, the Amish soon began to start their own communities in numerous rural localities throughout southeastern Pennsylvania. By the time of the Civil War, there were Amish communities as far west as Iowa, as far north as New York (and into the Canadian province of Ontario) and as far south as Maryland and what would become the state of West Virginia (Beachy, 2011; Hostetler, 1993). Augmented by continued migration throughout the $19^{\text {th }}$ century, the Amish population gradually increased, and stood at about 5,000 in 1900, living in 26 communities located mostly in the Midwestern region of the U.S.

Through the $20^{\text {th }}$ century, however, their population began to grow more rapidly, and with it the number of communities. By 1949, there were 49 communities, and in 1969 there were 94. At about this time, something akin to a population explosion began. Over the next twenty years, the number of communities more than doubled to 206, and doubled again to 411 in 2009 (Donnermeyer \& Cooksey, 2010). Amish communities today can be found from Maine to Mississippi to Montana, and most states in-between. Their current population stands at about 250,000 , and is expected to double again in the next 20-25 years (Donnermeyer \& Cooksey, 2010).

From their beginning, the Amish sought to be distinctive from the mainstream societies of their times. Their dress was less fancy, they conscientiously avoided military service, and sought out a rural, mostly agrarian lifestyle (Hostetler, 1993). As well, the social organization of the Amish has not changed much over their 300 plus year plus history. They still insist on adult baptism, which makes the rearing of their young into the faith essential to their growth, as few outsiders convert to their unique beliefs and lifestyle. Each church group (called a "church district" by the Amish themselves) is a small collection of 25-35 families who select their elders - a bishop, a deacon, and two ministers - through a process of nominating men who are then chosen by lot. Hence, there is no formal training of leaders.

Each church group determines its own church discipline, which in the Pennsylvania Dutch dialect spoken by the Amish is called the ordnung. It is the set of expectations by which the Amish live. Since there is no church hierarchy beyond the elders in each church group, the ordnung can vary from one church group to the next. Today, there are over 1,800 separate church groups, each of whom independently determines their ordnung.

The Amish eschew church buildings in favor or rotating their bi-weekly Sunday service from residence to residence of family members. The families live close enough to each other so that 
any one family can travel by horse and buggy to all other families in the same church district. Hence, their communities are not segregated colonies, but are better described as a cluster of families who live in physical proximity for the purposes of worship, socializing, and mutual support. In most localities, they are greatly outnumbered by "the English," a moniker they ascribe to anyone who is not Amish (Hostetler, 1993; Kraybill, 1989).

Each community (called a "settlement" by the Amish) consists of one or more church districts. A few settlements are quite large, consisting of 100 plus church groups, such as the greater Holmes County in northeast Ohio, the Lancaster/Chester County settlement in southeast Pennsylvania (also the oldest settlement in existence today), and the Elkhart-LaGrange-Noble County settlement in northern Indiana. The vast majority of settlements, however, are small with less than 4 church districts and 100 families (Donnermeyer \& Cooksey, 2010).

\section{Population Growth, Cultural Diversity, and the Diffusion of Amish Culture into Mainstream U.S.}

The Amish population and community are fueled by two primary factors. First, they have maintained high rates of fertility (Wasao \& Donnermeyer, 1992) even though most Amish families today do not depend on farming or agriculture for a living (Hurst \& McConnell, 2010). This makes the Amish a true exception to almost every other society in the world, who reduce their fertility as their economic base industrializes (Kreps, Donnermeyer, \& Kreps, 1994). Second, throughout the second half of the $20^{\text {th }}$ century, due in large part to the growing differences between mainstream American society and the Amish lifestyle, a growing percentage of young men and women born into Amish families decide to remain Amish when they reach the age of decision/baptism, rather than to jump over to a non-Amish way of life and an affiliation with a non-Amish church. The rate of baptism is now estimated to be about 90 percent, which when combined with constantly high fertility, creates dramatic population and compels the Amish to continuously seek out rural places where new communities can be founded (Greska \& Korbin, 2002; Stevick, 2007).

Many of these new communities are in counties where there is already one or more Amish settlements. However, over the past two decades, about 155 counties now play host to an Amish community where the Amish have never gone before (Donnermeyer \& Cooksey, 2010). This means that there are many places in the U.S. and Ontario where local authorities, including extension educators, must deal with a religious subculture of distinctive beliefs and practices with whom they may be unfamiliar.

Complicating the situation even more is a growing diversity of the ordnung. There were several major subdivisions among the Amish during the $20^{\text {th }}$ century, forming separate fellowships, or denominations. Some are very resistance to modern technology, such as the Swartzentruber Amish, who believe it is too worldly to place the orange slow-moving vehicle sign on the backs of their buggies, and will not allow such elementary household conveniences as linoleum floors and indoor plumbing. On the other end of the continuum are the New Order Amish, some of who now allow electricity in their homes and use cell phones and computers to manage their business (Hurst \& McConnell, 2010; Kraybill, 1994), all the while identifying as Amish and maintaining the semblance of a horse and buggy lifestyle.

\section{Amish Connection to an Agrarian Lifestyle}

While not always the primary income source for the Amish family, agriculture is part of their everyday lifestyle. And typical to this environment, rural families have opportunity to encounter 
farm ponds and flowing streams, livestock and horses, and other rural hazards that may not exist in city or town environments.

Many Conservative Anabaptist youth, especially the Amish, are exposed to farming and workrelated responsibilities at early ages; children begin daily chores by age five and drive teams of horses before age 10 (Kraybill, 1989). The inclusion of children into the family farm and various non-farm businesses at an early age suggests a higher probability of childhood injuries or fatalities. However, a study by Jones and Field (2002) indicated Amish lifestyles could be considered a protective factor in that their restraint from operating dangerous equipment, specifically ATV's, motorcycles, and snowmobiles, may actually lower their potential for injury and fatality. This same study indicated a lack of published data on morbidity and mortality in the Amish population, citing low participation in health and disability insurance programs where typical surveillance activities occur. The known data in existence shows that falls, animals, chemicals, and equipment are contributing factors to sustained injuries (Hubler \& Hupcey, 2002; Rhodes \& Hupcey, 2000).

Many Amish families participate in safety and health related programming conducted by their Amish Safety Committee. Likewise, Amish families attend community health fairs and hospital outreach programs aimed at prevention and general health. This trend makes one believe there is a prevailing interest in health promotion and injury prevention, albeit formerly undocumented. Rhodes and Hupcey (2000) commented that the Amish view their children as "gifts of God" and want their children to be safe and protected from harm. Yet there is a reoccurring gap in educational curricula designed for this age group (Hubler \& Hupcey, 2002; Jones \& Field, 2002).

To address the disproportion of knowledge and training resources, this study explored the perceived farm hazards facing Amish youth. Like other conservative Anabaptist groups who still abide by a horse-and-buggy lifestyle, religious beliefs compel the Amish to stay physically and symbolically separate from the world (Stevick, 2007). This includes living in a rural setting and a strong preference for farming and other home-based businesses to support the family. Although there is an emphasis on manual labor and pressure to avoid modern technology, the youth within conservative Anabaptist groups are exposed to a variety of materials, tools, and various machinery that pose potential hazards (Jones \& Field, 2002; Kraybill, 1989; Olshan, 1994).

\section{Methods}

Qualitative research, specifically focus groups, was the best approach taken by researchers to examine child safety issues within the cultural context of Amish society. This style of data collection provided a richer yield of collective information compared to that of personal interviews (Asbury, 1995; Murphy, Cockburn \& Murphy, 1992; Thomas, S., Steven, I., Browning, C., Dickens, E., Eckerman, L., \& Pollard, S., 1992). An 8-item discussion guide was adapted from an earlier tested instrument (Beaudreault, Jepsen, \& Dellinger, 2009) and used at each session, following a protocol approved by the OSU Institutional Review Board. To respect the Amish culture, audiotape technology was not used; rather, hand-scribed notes were taken by the moderator and assistant moderator, and in some locations, a third member of the research team.

A frame of key Amish community leaders was compiled using a combination of directories known by the research team. This frame contained names and addresses of church district leaders, members of state and national Amish Safety Committees, and persons whom 
researchers had established positive working relationships. These contacts received letters through the U.S. mail, describing the research project and asking for support to recruit members in the 5-state area to participate in the focus groups. Often times these key leaders were involved in coordinating a focus group in their area, and other times they connected the research team with a different informant in a neighboring community.

Once a primary contact was established for a particular geographic region, the Amish leaders worked cooperatively with the research team to recruit appropriate focus group members. Research protocol pre-identified the types of participants needed for a good cross-section of knowledgeable informants; six to ten community members were recruited, having representation from farmers, teachers, community leaders, and school board members. The key leaders played an instrumental role in both the identification and recruitment of these focus group participants. Letters were sent to each key leader following the recruitment process, confirming the date, time, and location of the session, with each session scheduled for a twohour period.

Focus groups were conducted in Ohio, Pennsylvania, Indiana, New York, and Kentucky. These states were chosen based on their large Amish populations. Ohio, Pennsylvania, and Indiana are home to slightly less than two-thirds of the total Amish population (Donnermeyer, 2011; Luthy, 2009; Young Center for Anabaptist and Pietist Studies, 2010). New York and Kentucky were selected as sites representing smaller populated states, yet geographically close in proximity to the other locations and as states where many new Amish settlements were being founded in response to their rapid population group (Donnermeyer \& Cooksey, 2010).

\section{Results}

Qualitative data was collected from 68 participants attending nine focus group sessions. Groups ranged in size from five to ten participants, encompassing views of Amish Safety Committee members, bishops, school board members, schoolteachers, production agriculture farmers, produce growers, and woodworking manufacturers; many were also parents and grandparents. The majority of participants (75\%) were males.

The first research objective was to generate a list of farm safety topics relevant to their children and the types of hazards to which these children may be exposed. Researchers aggregated the data under six broader themes of Equipment, Structures, Road, Water, Tasks/Chores, and Other (Table 1). Under each primary theme, participants identified sub-themes. For example, within the Equipment theme, tractor safety was a sub-theme that encompassed additional hazard topics including extra riders, riding in loader buckets, and power take-offs (PTOs). During the discussion, participants did not generate a list of topics in a linear fashion, nor did they always associate the topics as farm safety hazards; the protocol encouraged brainstorming from multiple perspectives of their children's environment, ranging from community safety, school safety, home safety, and farm safety. Discussion varied in length on the various themes - often using stories from past injury events as a means of recall. 
Table 1

Rural Safety Themes and Associated Topics

\begin{tabular}{|c|c|c|c|c|c|}
\hline Equipment & Structures & Road & Water & Tasks/Chores & Other \\
\hline $\begin{array}{c}\text { Lawn } \\
\text { Mower/String } \\
\text { Trimmers }\end{array}$ & Manure Pits & Walking & Swimming & $\begin{array}{c}\text { Mixing/Handling } \\
\text { Chemicals }\end{array}$ & Burns \\
\hline $\begin{array}{c}\text { Skid Steers/ } \\
\text { Loaders }\end{array}$ & Silos & Buggy & Fishing & Livestock & Weather \\
\hline Tractors & Hay Holes & Pony Carts & Ice skating & Gardening & $\begin{array}{c}\text { Wild } \\
\text { Animals }\end{array}$ \\
\hline Feed Carts & & & Ponds & Shop Work & Household \\
\hline
\end{tabular}

The second research objective was to determine age- and gender-appropriate tasks for the Amish children. When asked, "At what age do children start doing farm chores?" participants easily identified ages $3-5$ years as the range for chores performed by younger children. These chores included bottle-feeding calves, collecting eggs, and weeding gardens. Toddlers perform these chores while accompanied by an adult or older sibling.

At 8 years of age, children were given tasks involving livestock. Many of these assignments included feeding hay by hand, cleaning stalls, prepping cows for milking and other help within the milk house. Age 8 was also a time when children used pony carts, and in many cases, these carts were reported to operate on the road.

Between ages 10 - 12, children were given chores that involved power equipment. Children on dairy farms were reported using motorized feed carts as young as age 10. Powered lawn mowers and string trimmers were used by ages $11-12$. Skid loaders were identified in six focus group sessions as an item children operated. When asked the typical age youth began using these machines, four of the six groups answered age 10, while one group was adamant that the child be at least 16 years old.

Fourteen was a consistent age reported at all focus group sessions that youth operated horsedrawn buggies. The participants indicated prior to this age, youth were riding with their families, or did not have the need to be traveling alone. Roadway safety was a universal topic taught in many school districts, and was a topic commonly discussed in the community. Buggy safety was also a regular topic of family discussion, especially during times of operation when the families had opportunities to observe horse-driving behaviors, near-miss crashes, and other incidents related to highway travel. 
Table 2

Reported Age Amish Children Perform Farm Chores

\begin{tabular}{|c|c|c|}
\hline Chore & Age Range in years & Mode Age by year \\
\hline Bottle feeding calves & $3-5$ & $\mathbf{3}$ \\
\hline Gathering eggs & $3-5$ & $\mathbf{4}$ \\
\hline $\begin{array}{c}\text { Feeding milk in buckets to } \\
\text { calves }\end{array}$ & $3-5$ & $\mathbf{5}$ \\
\hline Working around livestock & $8-10$ & $\mathbf{8}$ \\
\hline Driving with pony carts & $8-12$ & $\mathbf{8}$ \\
\hline Utilizing mechanized feed carts & $10-12$ & $\mathbf{1 0}$ \\
\hline Operating skid loaders & $10-16$ & $\mathbf{1 0}$ \\
\hline $\begin{array}{c}\text { Operating lawn mower/ string } \\
\text { trimmer }\end{array}$ & $11-12$ & $\mathbf{1 1}$ \\
\hline Driving horse-drawn buggy & 14 & $\mathbf{1 4}$ \\
\hline
\end{tabular}

Within all focus group discussions regarding age-appropriate tasks, it was difficult to identify a specific age for each farm chore. Participants reported that children are evaluated independently for the kind and size of task; decisions are often made on the basis of physical development, maturity, interest in the task, and birth-order.

Participants were also asked if gender played a role in farm chore assignment. The universal response to this question was "you use what you have in the family," meaning in a family blessed with all girls, the girls would be responsible for tasks that in another family would be a boy's responsibility. However researchers noted certain chores did appear to favor specific genders. Tasks like bottle-feeding calves, milking, and lawn mowing were chores more readily identified as chores for girls, while boys were given tasks involving hand labor, physical strength, and equipment operation (i.e. tractors, skid loaders, powered feed carts, and field implements).

The third research objective was to identify the types of educational resources preferred by Amish adults for their children, as well as educational programs that the children would attend. Participants reported on current educational delivery methods occurring in their communities. When a community had an Amish Safety Committee, participants reported many programs identified and sponsored by this group, including Amish Health and Safety Days, fire safety programs, home safety, and roadway safety. In other areas, participants identified local agencies that conducted programming, including fire safety programs by local fire departments, bicycle safety from the sheriff's office, and resources offered through their Cooperative Extension services. The focus group discussions also identified educational activities that could be offered to their youth; the two most popular approaches were hands-on demonstrations and workbooks that included matching activities, crossword puzzles, word searches, stories and coloring pages.

The structure of focus groups allowed for free-flowing opinions around a common discussion guide, providing a more open context for interpretation and sensitivity to group dynamics. 
Researchers believed these focus groups provided a solid foundation of information as little new information was gathered by the end of the ninth session.

\section{Discussion}

In any farm operation, variations occur in work practices, age of equipment, use and access to technology, and connection to public services. However, Amish settlements share similarities in that they embrace their rural lifestyle and include their large families and young children in common farm chores. The participants in this study recognized their rural lifestyle had hazards and acknowledged these risks.

Recommendations made by Jones and Field (2002) stated more culturally sensitive farm safety materials are needed for the Amish and other conservative Anabaptist communities, with special attention to material oriented towards children. Findings from this study can be used to develop such resources, as well as provide extension educators a better understanding of the involvement Amish children have in farm activities, and ultimately an opportunity to engage these youth in safety programs. The three broad categories discussed in this section are areas where youth development professionals can contribute their expertise.

\section{Suggestions for Safety Topics}

The qualitative data revolved around six main themes related to rural life and agricultural safety. Within these areas, four safety topics emerged as top concerns. Not surprising to researchers, each geographic region reported children needed more information and safety instruction on the common everyday items children encounter; such topics included water safety, lawn mowers, and string trimmers. Likewise, chemical safety was also identified, with little distinction between the kinds of chemicals (i.e. farm-use pesticides, garden pesticides, fertilizers, agricultural cleaning agents, and household cleaning products); chemical handling and respect for chemicals were two additional concerns for their children to understand.

Three topics that closely followed the first ranked items included confined spaces, skid loaders, and tractors. Focus group participants expressed the need for their children to learn about silo and manure gases, as this was a topic the adults didn't always understand. One participant commented, "If we knew what to tell the children, we would all be better off because of this knowledge." Tractor and skid loader safety was a highly reported topic where information was needed. Adults believed children should be made aware of these hazards regardless of their Ordnung and use of these machines.

Safety around livestock, horses, and pony carts were topics identified by focus groups, but without the intensity expected from the research team. Amish children, at very young ages, were reportedly exposed to poultry, livestock, ponies, and horses; injury reports document the need for safety education around these animals.

The hazards identified by this sample of participants was in alignment with the limited surveillance data that suggested Amish youth were injured and killed by falls, chemicals, and equipment (Hubler \& Hupcey, 2002; Rhodes \& Hupcey, 2000). Amish children within the focus group communities were exposed to a wide array of agricultural hazards, warranting a need for educational materials that address their specific exposures. 


\section{Effect of Age and Gender on Chore Assignment}

As reported by Kraybill (1989), Amish and other conservative Anabaptist communities are strongly rooted in family ties, often involving multiple generations in their daily workload. Children, at all ages, are encouraged to be involved with daily chores. When discussing the role of age and gender, focus group participants reported many tasks were assigned based on the child's physical development, maturity, and birth order. They provided supporting statements like: "Each child is different," and "Some are capable and some are not." These reports coincide with the Rhodes and Hupcey (2000) study discussing Amish parental judgment, developmental appropriateness, and family birth order as a means to determine a child's readiness for farm tasks.

Focus group participants had a difficult time recalling the age their own children began performing farm chores. When asked the typical age youth begin performing tasks, the common reaction was to turn the question back to the researchers, asking for their thoughts. This reaction was common with all focus group sessions, and researchers were careful not to guide answers, but rather waited for responses to naturally emerge from the group. Reasons for such hesitations were discussed in researcher debriefings; two potential conclusions were identified 1) either participants were intimated by the researcher's knowledge of the agricultural safety field, or 2) participants were fearful of judgment regarding the age they allowed their children to engage in hazardous farm tasks - criticisms by either the researchers, their neighbors, or their spouses in attendance. However, through probing questions used by the moderator, this hurdle was overcome and gave way to thoughtful discussion. Interesting for the safety researchers in the room to hear, several participants made direct suggestions that having age appropriate task recommendations would be helpful for some Amish parents.

Gender was a variable that made little impact on the assignment of farm chores. A male participant shared he had one daughter who would rather drive a tractor than do the milking, while another daughter had no interested in driving the tractor. Participants all stated each child's physical and mental development is a trait unique to them, and that oftentimes work is assigned based on physical strength and interest in the job. The significance of understanding this finding will be addressed when educational materials are developed, in that pictures can include both genders performing various tasks on the farm, and not be perceived offensive or an inaccurate portrayal of their lifestyle.

\section{Implications for Educational Resources}

Past research has indicated a gap in the educational programming and available resources for teaching agricultural safety in the Amish and other conservative Anabaptist population, especially topics focused towards children. Focus group participants were able to identify useful educational delivery methods and activities that Amish schoolteachers could incorporate into their classroom. They encouraged the development of a school-supported curriculum for teachers to deliver periodically throughout the school year and that such activity sheets would include a message for the parents. Participants felt this take-home message would lead to further conversation among family members, as well as encourage parents to role model safe behaviors.

\section{Opportunities to Partner with Community Stakeholders}

As new Amish settlements emerge in geographic regions where once they did not exist, Extension educators have the capacity to extend youth development programs to these communities, especially in areas of health and safety. Using a process long familiar to extension professionals is community asset mapping. This strategic approach identifies particular 
resources and stakeholders present in a community that can identify, shape, and define specific key issues of concern, as well as determine appropriate methods to implement educational programs and evaluations. A key attribute to the mapping process is identifying other stakeholder agencies that support the health of the community and can serve as partners, especially to create a multiplying effect on the target audience or target issue (Kretzmann \& McKnight, 1993).

With regards to injury prevention programs, many public health and safety collaborators exist in the local infrastructure and are natural partners to lead or assist with program planning with Amish populations. The obvious partners include fire departments, law enforcement, departments of health, and emergency management agencies. However, other agencies that have a vested interest in health and safety can include departments of natural resources, the game warden, the YMCA, Red Cross, hospital outreach programs, medical centers and private physicians, poison control centers, environmental protection agencies, and insurance agencies.

\section{Conclusion}

Children play a vital role in the family structure of the Amish and other conservative Anabaptist groups. This includes participation in daily-living chores as well as occupational-related tasks. Regardless of gender, children of all ages are involved in a variety of agricultural exposures and are at risk for injury. Amish groups support the development of agricultural safety curriculum specifically designed for preventing injury and illness in their children; and these resources should be age-appropriate, cultural-appropriate, and an accurate reflection of the risks children face. Such materials would be used by Amish Safety committee members when developing their own local safety programs; schoolteachers who need supplemental activities throughout the school year; as well as parents and grandparents who work beside the children needing stories or lessons to discuss. Educational resources should target topics where children have high exposure and high injury rates, areas such as lawn mowers and string trimmers, chemical handling, water safety, livestock, confined spaces, tractors and skid loaders.

Developing programs for Amish children, especially in regards to safety education and injury prevention is an area that Youth Development educators can make a positive impact and serve an area of need. By understanding the Amish subculture, it is likely extension educators can be successful in meeting the expressed needs of that community, which in turn may lead to future programming in other topic areas.

History, persistence, change, and diversity - these are the four key words necessary to understand the Amish culture. Many conservative Anabaptist groups, despite their outward appearances, are continuously changing and migrating. For that reason alone, a periodic assessment of the safety needs of their youth is imperative if program effectiveness is to be maintained.

\section{References}

Asbury, J. (1995). Overview of focus group research. Qualitative Health Research,5(4), 414420.

Beachy, L. (2011). Unser Leit: The Story of the Amish. Millersburg, Ohio: Goodly Heritage Books. 
Beaudreault, A., Jepsen, S.D., \& Dellinger, W.A. (2009). Designing an agricultural safety intervention program for Ohio Amish Youth. The Journal of Cases in Public Health Communication \& Marketing, 3.

Donnermeyer, J.F. (2011). County-level estimates of the Amish population in North America. Report to the Religious Congregations and Membership Study. Lenexa, Kansas: Association of Statisticians of American Religious Bodies.

Donnermeyer, J.F., \& Cooksey, E. (2010). On the Recent Growth of New Amish Settlements. Mennonite Quarterly Review, 84 (April), 181-2008.

Greska, L.P., \& Korbin J.E. (2002). Key Decisions in the Lives of Old Order Amish: Joining the Church and Migrating to Another Settlement. Mennonite Quarterly Review, 76 (October), 373398.

Hostetler, J.A. (1993). Amish Society ( $4^{\text {th }}$ ed.). Baltimore, Maryland: The Johns Hopkins University Press.

Hubler, C.L., \& Hupcey, J.E. (2002). Incidence and nature of farm-related injuries among Pennsylvania Amish children: Implications for education. Journal of Emergency Nursing, 28(4), 284-288.

Hurst, C.E., \& McConnell, D.L. (2010). An Amish Paradox: Diversity and Change in the World's Largest Amish Community. Baltimore, Maryland: The Johns Hopkins University Press.

Jones, P.J., \& Field, W.E. (2002). Farm safety issues in Old Order Anabaptist communities: Unique aspects and innovative intervention strategies. Journal of Agricultural Safety and Health $8(1), 67-81$.

Kraybill, D.B. (1989). The Riddle of Amish Culture. Baltimore, Maryland: The Johns Hopkins University Press.

Kraybill, D.B. (1994). Plotting Social Change Across Four Affiliations. Pp. 53-74 in Donald B. Kraybill \& Marc A. Olshan (eds.), The Amish Struggle with Modernity. Baltimore, Maryland: The Johns Hopkins University Press.

Kreps, G.M., Donnermeyer, J.F., \& Kreps, M.W. (1994). The Changing Occupational Structure of Amish Males. Rural Sociology, 59 (Winter), 708-719.

Kretzmann, J.P., \& McKnight, J.L. (1993). Building Communities from the Inside Out: A Path Toward Finding and Mobilizing a Community's Assets. Center for Urban Affairs and Policy Research, Neighborhood Innovations Network, Northwestern University, 2040 Sheridan Road, Evanston, IL.

Luthy, D. (2009). Amish settlements across America. LaGrange, Indiana: Pathway Publishers. MacDougall, C., \& Fudge, E. (2001). Planning and recruiting the sample for focus groups and indepth interviews. Qualitative Health Research. 11(1). 117-126. 
Murphy,B., Cockburn, J., \& Murphy, M. (1992). Focus groups in health research. Health Promotion Journal of Australia, 2(2). 37-40.

Nolt, S.M. (2003). A History of the Amish (rev. ed.). Intercourse, Pennsylvania: Good Books.

Olshan, M.A. (1994). Amish cottage industries as Trojan horse. Pp. 133-146 in D.B. Kraybill \& M.A. Olshan (eds.), The Amish struggle with modernity. Hanover, New Hampshire: University Press of New England.

Rhodes, D.A., \& Hupcey, J.E. (2000). The perception of farm safety and prevention issues among the Old Order Amish in Lancaster County, Pennsylvania. Journal of Agricultural Safety and Health, 6(3), 203-213.

Stevick, R.A. (2007). Growing Up Amish: The Teenage Years. Baltimore, Maryland: The Johns Hopkins University Press.

Thomas, S., Steven, I., Browning, C., Dickens, E., Eckerman, L., \& Pollard, S. (1992). Focus groups in health research: A methodological review. Annual Review of Health Social Sciences,2, 7-20.

Wasao, S.W., \& Donnermeyer, J.F. (1992). An Analysis of Factors Related to Parity Among the Amish in Northeast Ohio. Population Studies, 50 (\#2), 235-246.

Young Center for Anabaptist and Pietist Studies. (2010). Elizabethtown College The Twe/ve Largest Amish Settlements. Retrieved on March 5, 2011 from

http://www2.etown.edu/amishstudies/Largest Settlements 2010.asp.

(C) Copyright of Journal of Youth Development Bridging Research and Practice. Content may not be copied or emailed to multiple sites or posted to a listserv without copyright holder's express written permission. However, users may print, download or email articles for individual use. 